\title{
SAJANDID KÄEULATUSES: VANAD GRAMMATIKAD EESTI KEELES
}

\author{
HELI LAANEKASK
}

\begin{abstract}
Annotatsioon. Artiklis analüüsitakse XVII-XIX sajandi võõrkeelsete eesti keele grammatikate nüüdseks ilmunud tõlkeid eesti keelde ning nendes grammatikates leiduvate mitmekeelsete sõnastike uusväljaandeid. Kirjutise keskmes on V-L. Kingisepa, K. Ressi ja K. Tafenau „Heinrich Gösekeni grammatika ja sõnastik 350" (Tartu, 2010), kuid käsitletakse ka M. Lepajõe Gutslaffi-tõlget (J. Gutslaff, „Observationis grammaticae circa linguam Esthonicam. Grammatilisi vaatlusi eesti keelest", Tartu, 1998), I. Annomi Wiedemanni-tõlget (F. J. Wiedemann, „Uurimus Võru murdest”, Tartu, 2002), K. Kikase uurimust „Mida sisaldab Heinrich Stahli Vocabula?" (Tartu, 2002), K. Rossi jt tõlgitud Ahrensi grammatikat raamatus „Uue ajastu misjonilingvist. Eduard Ahrens 200” (Tallinn, 2003) ning A. Kilgi ja K. Rossi Thor Helle-tõlget nende raamatus „Lühike sissejuhatus eesti keelde 1732" (Tallinn, 2006). Vaadeldakse nende tõlketeoste struktuuri ja kommentaariumi ning vaetakse eri lahendusi omaaegse terminoloogia tõlkimisel, arhailise eesti keele seletamisel ja sõnastike keelevaramu avamisel.
\end{abstract}

Võtmesõnad: eesti keele grammatikakirjeldus, eesti leksikograafia, mitmekeelsed sõnastikud, eesti kirjakeele ajalugu, tõlkimine, tekstikriitiline editsioon

2010. aasta lõpul ilmus trükist sisukas juubeliüllitis, Valve-Liivi Kingisepa, Kristel Ressi ja Kai Tafenau „Heinrich Gösekeni grammatika ja sõnastik 350”, mille on toimetanud Külli Habicht ja Külli Prillop. Raamatu 768 leheküljele on mahutatud Heinrich Gösekeni „Manuductio ad Linguam Oesthonicam, Anführung Zur Öhstnischen Sprache” (Reval, 1660) tiitellehe, sissejuhatavate osade ja grammatika faksiimile koos kõrvutise eesti ümberpanekuga (tõlkija Kai Tafenau, lk 38-301) ning sama teose sõnastikuosa, mis on aga esitatud keelesuunda muutes, eestisaksa-ladina leksikonina (koostajad Valve-Liivi Kingisepp ja Kristel Ress, lk 307-768). Sõnastikuosa on toimetanud Kai Tafenau (Habicht 2010: 8). Peale grammatikatõlke ja ümberpööratud sõnastiku on raamatus muidki 
kommentaariumiosi: Habichti „Saateks” (lk 7-10), Kingisepa „Heinrich Gösekenist eesti kultuuriloos” (1k 11-26), Ressi „Sõnaraamatu kasutajale” (1k 27-35) ning Tafenau „Heinrich Gösekeni grammatika tõlkest” (lk 36) koos kommentaaridega (lk 302-306). Saateartiklist ilmneb, et just sõnastikuosa juures on algul abiks olnud ka Argo Mund, Piret Sõmermaa ja Kadri Kerner (Habicht 2010: 8), keda tiitellehel siiski pole autoritena mainitud. Toimetustööst rääkides on Habicht rõhutanud Tafenau osa saksa ja ladina keele asjatundjana ning esile tõstnud Prillopit arvutispetsialistina, kuid tagasihoidlikult jätnud mainimata enda rolli juubeliteose ühisel koostamisel ja toimetamisel.

Ilmselt köite mahupiiride tõttu pole sisse võetud Gösekeni teose algupärast saksa-ladina-eesti sõnastikuosa. Tõsi küll, Gösekeni „Manuductio” faksiimile on juba varem tervikuna avaldatud Hamburgis (Värri Haarmann 1977) ja kogu „Manuductiot” saab lugeda ka internetist Eesti Kirjandusmuuseumi digitaalraamatukogu kaudu ${ }^{1}$. Kasutajana meeldivad mulle siiski rohkem sellised lahendused, kus originaalteos on taasesitatud tervikuna ning algupärandi ja kommentaariumi kõrvutiseks lugemiseks pole vaja liiga palju edasi-tagasi lehitseda või arvutiklahve klõpsida. Köite mahu ja struktuuri peale mõeldes võinuks selles praegu sisalduva eesti-saksa-ladina sõnastiku esitada ehk omaette raamatuna? Tegemist on vaieldamatult väga väärtusliku uurimusega, kus muudetud keelesuund ja nüüdisajastatud märksõnad tõstavad paremini esile Gösekeni „Manuductio” sõnastikuosa rikkalikku eesti leksikat, võimaldades selle arvutianalüüsi ja liitmist vana kirjakeele korpusesse. Sinna köitesse oleks võinud paigutada ka kommentaariumisse kuuluva saksa- ja ladinakeelsete sõnade registri, mis samuti pole praeguses väljaandes kohta leidnud. Loodame, et seda registrit on võimalik kasutada hiljem vana kirjakeele korpuse veebiaadressil, nagu toimetaja on lubanud (Habicht 2010: 7).

Vanade grammatikate tõlkimisega on Eestis tegeldud varemgi. Juba XIX sajandi algupoolel on Kristian Jaak Peterson mugandades tõlkinud saksa keelde Johannes Gutslaffi grammatika (1648); käsikirja säilitatakse Eesti Kirjandusmuuseumis (KM EKLA, f 192, m 109). Sama grammatika saksa tõlke on kavatsenud üllitada ka Beiträge väljaandja Johann Heinrich Rosenplänteri vend, jurist Friedrich Bernhard Rosenplänter, kuid rahapuudusel on plaan luhtunud; käsikirja edasine saatus on teadmata. (Lepajõe 1998c: 280) Uuemaaegne eestvõtja-taganttõukaja oli professor

\footnotetext{
http://www2.kirmus.ee/grafo/
} 
Huno Rätsep: tema juhendatav Marju Lepajõe tõlkis sama grammatika (ja kommenteeris seda) Tartu ülikooli diplomitööna (Lepajõe 1985). Täiendatud kujul ilmus seegi töö sobivalt märkima grammatika 350 aasta juubelit, niisiis: Gutslaffi „Observationes grammaticae” faksiimile koos Lepajõe paralleelse ümberpanekuga ja tõlkija ning Hella Keema muu kommentaariumiga (Gutslaff 1998). Seejärel on avaldatud teisigi vanemate keeleraamatute tõlkeid: Wiedemanni „Versuch ueber den werroehstnischen Dialekt" (1864) koos kõrvutise faksiimilega, tõlkija Inge Annom (Wiedemann 2002); Eduard Ahrensi „Grammatik der Ehstnischen Sprache Revalschen Dialektes" (1853), kahjuks ilma faksiimileta, tõlkijad Kristiina Ross, Kristi Mets, Kristiina Rebane ja Mailis Salvet (Ross 2003: 75-429). Seevastu Anton Thor Helle „Kurtzgefaßte Anweisung Zur Ehstnischen Sprache" (1732) tõlke on ümberpanijad-kommenteerijad Annika Kilgi ja Kristiina Ross publitseerinud koos lugejale väga käepärase paralleelse äratrükiga originaalist (Kilgi, Ross 2006). Seni viimane selles tõlgete reas on Wiedemanni „Grammatik der ehstnischen Sprache” (1875) ümberpanek siinkirjutajalt (Wiedemann 2011). Paraku tuleb ka selle tõlke lugejal, kui ta soovib midagi täpsustada, eraldi pöörduda kas originaalväljaande või hiljutise faksiimiletrüki poole (Wiedemann 2005).

Mis puutub XVII-XVIII sajandi grammatikates leiduvatesse sõnastikesse, siis neid on uusväljaannetes esitatud mitmel kombel. Otstarbekohane tundub Lepajõe lahendus: Gutslaffi saksa(-ladina)-eesti leksikoniosa on esitatud faksiimilena (Gutslaff 1998: 206-246), sellele järgneb koostajatõlkija tehtud tähestikuline register kõigist grammatikas esinevatest eesti sõnadest koos viitega uusväljaande leheküljele (Lepajõe 1998a). Ka Thor Helle grammatika eesti-saksa sõnastik koos saksa sõnade registriga ja muude lisadega on esitatud faksiimilena (Kilgi, Ross 2006: 83-419); sellele järgnevad sõnastiku lisades jm esinevate saksakeelsete lõikude tõlked Rossilt, järjestatud esinemislehekülje järgi (Kilgi, Ross 2006: C1-C5), ning paar lehekülge kommentaare (Kilgi, Ross 2006: C6-C7). Muidugi on originaali jäljendtrükil praeguse lugeja silmis omad puudused: sageli on tekstileheküljed veelgi tuhmimad ja kustunumad kui originaalis, fraktuurkirjast ja vanadest ortogrammidest ei pruugi aru saada ning saksa- või ladinakeelsed märksõnad või tõlkevasted jäävad keeleoskamatuse tõttu hämaraks. Vanade sõnastike keelevaramu on nii otsekui kivi taga peidus.

Nõudliku sammu edasi on teinud Tartu Ülikoolis tegutsev vana kirjakeele töörühm, mille liikmed Valve-Liivi Kingisepa eestvõttel ja 
juhendamisel (vt selle kohta lähemalt Kingisepp 2002) on hakanud koostama ja publitseerima muudetud keelesuunaga leksikone. Esimesena ilmus sellisel kujul Stahli grammatika „Anführung zu der Ehstnischen Sprach” (1637) sõnastikuosa, mille oli magistritööna kokku seadnud Kristel Kikas (2002). Vanast sõnastikust uue koostamise käimata teel on see uurimus olnud omamoodi rajaleidja. On tulnud otsustada, kuidas käituda originaalis leiduvate eesti vastete vormistikuga, mitmeosaliste saksa märksõnadega ja nende sageli sünonüümsete eesti vastetega, kuidas edastada sõnapesi, kuidas tõlgendada liitsõnapiiri ja üldse omaaegset ortograafiat, kas ja kuidas nüüdisajastada uue märksõna häälikkuju, milliseid tähendusseletusi anda, kuidas määrata sõnaliiki, fraasi või lausekonstruktsiooni, mida teha originaalis leiduvate kommentaaridega, kui palju kasutada viitemärksõnu, missuguseid kommentaariumiosi uuele sõnastikule lisada jne. Peale teoreetiliste arutluste ja arukate praktiliste lahenduste selles uurimuses (Kikas 2002) on autor (praeguse nimega Kristel Ress) seda probleemipundart harutanud ka eraldi artiklis (Ress 2009), kus palju näitematerjali on pärit just Gösekeni teosest. Teine samal kombel Tartus valminud sõnastik, Johannes Gutslaffi keeleõpetuse leksikoniosa pöördvariant (Viitkar 2005), on üliõpilastööna jäänud esialgu käsikirja (Ress 2009: 631) - soovigem tegijatele jõudu selle lõppviimistluseks enne ilmumist. Gösekeni juubeliväljaandes ilmunu on niisiis valmimisjärjekorras kolmas, kuid ilmumisjärjekorras teine omataoline. Kaht ilmunut võrreldes märkame, kuidas töö on tegijaid õpetanud: näiteks on Gösekeni pöördsõnastikust õigustatult ära jäetud tärn, millega Stahli pöördsõnastikus oli märgitud tänapäevastest vormiliselt või sisuliselt erinevaid märksõnu (vrd Kikas 2002: 29; Ress 2009: 634-635; Ress 2010); ka on Gösekeni pöördleksikonis Stahli omast harvem välja kirjutatud sõnaosi, mis originaalis ruumi kokkuhoiu tõttu puuduvad (Ress 2009: 636) jne.

Tahaksin seoses märksõnastamisega põgusalt puudutada probleemi, mille üle olen mõelnud muugi vana kirjakeele korpusesse paigutatava materjali puhul. See on nimelt omaaegsete sõnakujude ja vormide vastavus praegusaegsetele ja varasemate kujude kajastamine praeguses märksõnastikus. Soovides kunagisi sõnakujusid nüüdsetega seostada, on printsiibiks seatud, et märksõnaks valitakse võimaluse korral tänapäeva eesti keele sõna oma põhivormis (Kikas 2002: 28-29; Habicht jt 2006: 371-375; Ress 2010: 28-29). Gösekeni hatt 'naiste peakate' on niisiis märksõnastatud kujul att ja Gösekeni Markal 'marssal' on saanud märk- 
sõnaks marssal (Ress 2010: 28). Kasutajana tahaksin sellisel puhul uues sõnastikus siiski näha viitemärksõnu hatt $\rightarrow$ att ja markal $\rightarrow$ marssal, neid aga pole. Gösekeni Pallast oleks nüüdisortograafiasse transkribeerituna pallast või isegi palast 'ballast'; pöördsõnastikus on märksõnaks vaid tänapäevane ballast, $p$-ga algavat viitemärksõna pole. ${ }^{2}$ Gösekeni opper on märksõnastatud kujul ohver, viitemärksõna taas pole. Tundub, et tüvesid on märksõnastamisel võrreldes liidetega julgemini nüüdisajastatud, mõnikord küsitavaltki. Gösekeni grafeem kaugkel wachtama oleks nüüdistranskriptsioonis kaugel vahtama, tähenduseks 'kaugele vaatama'. Viitemärksõnu kaugel vahtama $\rightarrow$ kaugele vaatama või vahtama $\rightarrow$ vaatama pöördsõnastikust ometi ei leia, seal on märksõnadena vaid kaugele vaatama ja vaatama. Arvan ka, et nt Gösekeni variant parramdama (parrandama kõrval, tähenduses 'parandama') ei pruugi olla trükiviga (vrd Ress 2010: 29), nagu seda ei tarvitse olla ka habenetta 'habemeta' (vrd Ress 2009: 632). Onomatopoeetilised ja deskriptiivsõnad võivad teatavasti olla üpris varieeruva tüvekujuga, Gösekeni grafeemide hissetama ja hissitama 'koeri ässitama' märksõnaks valitud ässitama on seetõttu kahtlane; vähemalt viitemärksõnadena võinuks esimesed kaks alfabeetiliselt reastatud märksõnade hulka jääda. Endisaegset vokalismi on küll eriti täbar tõlgendada, kuid siiski: tuleleegi või -lõõma märkimiseks on Göseken kasutanud mh grafeeme löchk ja löhk; neist esimest ei märksõnastaks ma kujul lõog (vrd Ress 2010: 28), vaid pigem kujul lõhk või lehk. Kas märksõnaks nimetavalise või omastavalise liitumisega sõna? Näiteks on katuselauda tähistavaks märksõnaks valitud kisklaud, aga Gösekeni grafeem on kisso laud; lumepalli tähistab märksõna lumekäkk, ent Gösekenil on saksa Ball juures ka sõna Schnee-Ball koos eesti vastega Lummi keck. Mis puutub sõnatuletusse, siis sel puhul on lubatud, et märksõnastamisel liiteid ei lisata ega jäeta ära (Kikas 2002: 29; selgemalt Ress 2010: 28) ja nii on üldiselt ka tehtud. Gösekeni hahrima on siiski märksõnastatud kujul haarama, mitte haarima, löhtzma märksõnaks on lõotsuma, mitte lõotsma, tassast on tasasti, mitte tasast jne.

Viitemärksõnad muidugi paisutaksid pabersõnastiku mahtu, seepärast loodan, et vähemalt arvutivariandis (vt selle kohta nt Prillop 2004) on ehk võimalik ka endisaegsetest sõnakujudest süstemaatiline ülevaade saada. Õnnelik tuleb olla selle üle, et vanade sõnastike märksõnapesade

2 Vana ortogramm ja häälduskuju on tänapäevalgi muide säilinud Tallinnas Lasnamäe tänavanimes Pallasti (rõhuga esisilbil). 
lahtiharutamisel ja alfabeetilisel järjestamisel on uues sõnastikus nüüd kokku saanud sama tuumsõnaga väljendid (vt näiteks märksõnaartiklit olema, Kingisepp jt 2010: 536-538), samuti homonüümid. Leppida tuleb aga sellega, et algtekstis sünonüümidena esitatu on nüüd enamasti lahutatud: nt Gösekeni saksa väljendi Backenstreich geben 'kõrvakiilu andma' eesti vasted suu pehle löhma ja körwa ehre löhma (märksõnastatult vastavalt suu peale lööma ja kõrva äärde lööma) on eri kohtades ja ilma saksa sõnaregistrita on kasutajal võimatu teada, et neil väljenditel on sama vaste. Vaid siis, kui Göseken on sünonüümi tähistanud mingi metakommentaariga (nt ladina item, lühend it. 'sama'), saame sarnassõnast aimu, sest autori metakommentaarid on uues sõnastikus kiiduväärselt lubatud säilitada (nt märksõnaartiklis lutikas on säilitatud Gösekeni märkus it. punnane sax).

Mõeldes tänapäevase kasutaja peale, kelle saksa või ladina keele oskus on kehv või päris olematu, võinuks uues leksikonis ehk mõnikord kaaluda ka eesti tõlkevaste andmist. Nt fraasilise märksõna papi külimit ning kotisopp ei saa iial täis saksa vastet des Rigen Pappen külmet und Sacks Winckel werden nimmer voll lugedes saab selgeks, et tegelikult tähendab papp selles väljendis rehepappi; kas see tähendus peaks kajastuma ka märksõnaartiklis papp (praegu seda seal pole)? Teine näide: märksõnaartiklis luukamber olev Gösekeni tore seletus Scheitel stete / da die Todten köpffe liegen (als Beinhaus) jääb umbkeelsetele hämaraks. Veelgi udusemaks muutub asi siis, kui avame seal viidatud lehekülje 395 (õieti küll 396) Gösekeni 1660. aasta „Manuductiost” ja loeme kogu algset sõnapesa: et aru saada, kuidas see lahti on harutatud, peaks kindlasti oskama ka ladina keelt. Jääb vaid üle usaldada asjatundjaid ja nii me teemegi.

Sellega olemegi jõudnud teise suure küsimusteringi juurde vanade grammatikate käepäraseks tegemisel: kuidas neid tõlkida? Tõlge on ju tegelikult osa kommentaariumist, niisiis võime kohe mõelda muudegi kommentaariumi osade peale. Tõlkimine on universaalne tegevus, mille kohta on tohutult nii praktilisi näpunäiteid kui ka teaduskirjandust, mida kõike võiks lõpuks kokku võtta ühte suurde küsimusse. Kas tõlkida sõna või mõtet? Ja vastus on: tuleb tõlkida mõtet. Ent iga päriselt tõlkimisega tegelenu teab, et sõnast ei pääse, sõna ongi mõte. Teadusliku teksti tõlkimisel tuleb näiteks otsustada, mida teha omaaegsete terminitega. Termin pole ju ainult sõna, selles kajastub ka varasem teadmiste ulatus ja liigendus. Vanad terminid vajavad tõlkes säilitamise korral kom- 
mentaari, nagu vajavad selgitusi ka muud esile tulevad asjad: teosed, isikud, seosed jne. Kriitilise ehk teadusliku editsiooni juurde kuuluvadki kindlasti nii keele- kui ka reaalkommentaarid ning mitmesugused saateartiklid.

Meie vanade grammatikate tõlkimise pioneeri Marju Lepajõe tabavat tähelepanekut laiendades võime öelda, et omi vanu kirjalikke tekste uurides oleme õnnelikus olukorras: uurimusi on suhteliselt vähe, tekstid on tähendustega koormamata (vrd Lepajõe 1998b: 285). Tõepoolest pole meil vaja end läbi kaevata sellisest kirjasõnamäest, mis on ees antiikkirjanduse uurijatel või piiblitekstide tõlgendusega tegelejatel. Mis on sealsete tuhandete kõrval nt 61 kirjutist Thor Helle kohta (vt Kilk, Ross 2006: C57-C63)! Kuid peame arvestama sedagi, et meie tööd saavad erilise kaalu ja mõju: Lepajõe Gutslaffi-tõlget ja seletusi, Kilgi-Rossi Thor Helle-ümberpanekut ning kommentaare või Kingisepa jt Gösekeni-tõlgendusi kasutatakse ilmselt veel ka järgmisel sajandil. Tõdemused, mis on välja öeldud nt Huno Rätsepa artiklis Heinrich Stahli grammatika kohta (Rätsep 1987) või Lepajõe Gutslaffi-saateartiklites (nt misjonilingvistika kohta kirjutatu, Lepajõe 1998b: 294 jj) tunduvad praegu juba nii iseenesestmõistetavana, et nendele kirjutistele vahel enam isegi ei viidata. Gösekeni grammatikat tõlkides on Tafenau saanud toetuda Lepajõe lahendustele, Wiedemanni grammatikat ümber pannes vaatasin ühtelugu Rossi jt Ahrensi-tõlget jne. Peamurdmist vana grammatika tõlkijal igatahes jätkub, ka siis, kui ta on otsustanud endisaegse terminoloogia säilitada: nt originaalteksti väljalugemine, oletatavatele trükivigadele jm lapsustele osutamine, interpunktsiooni ja šriftide edasiandmine, kohanimede tõlkimine, isikunimede õigekiri, algupärandi eri keelte kajastamine (kas tõlkida kõik ühtlaselt eesti keelde või näidata eesti ümberpanekuski seda, et nt saksa lähtekeelses tekstis on ka heebrea, kreeka, ladina, läti, soome jms võimalikke keeli - eesti- või segakeelsetest osadest rääkimata) jne. Üllatavalt täbaraks võivad osutuda eestikeelsete näidete autoritõlked: kas neid on vaja tagasi tõlkida või mitte? Ja kas ka omaaegne eesti keel vajaks kommentaare? See, et uue teksti ja kogu väljaandegi struktuur kipub minema keeruliseks, on kõigi tekstikriitiliste üllitiste ühine mure. Mulle tundub, et mitmeid probleeme on veidi lihtsam lahendada, kui tõlketekstiga kõrvuti on lugejal võimalik jälgida ka faksiimilet. Igal juhul on nii lihtsam märgata neid kohti, mida ise sõnastaksid teisiti (selles pole midagi ebaharilikku, on ju keel juba oma olemuselt sünonüümne) või - vähemalt enda arvates - õigemini. Näiteks 
kui loen tõlkest vrd ülal ja eestpoolt midagi sobivat ei leia, siis läheb süda kergemaks, kui näen, et kõrvutises faksiimiles seisab vergl. unten 'vrd allpool' (vrd Wiedemann 2002: 16-17).

Kui seni oled üht või teist vana grammatika võõrkeelset tekstikohta mõttes nii- ja teistpidi keeranud, ohates sõnaraamatu järele haaranud ja ikkagi oma arusaamises mitte päris kindel olnud, siis on tõeline nauding lugeda ladusas ümberpanekus, läbimõeldud graafilises esituses ning asjatundlike seletustega terviktekste kõrvuti faksiimilega. Just sellised on Lepajõe, Kilgi-Rossi ja Tafenau tõlked. Juba dedikatsioonide pöördumised (nt Kingisepp jt 2010: 40-53) mõjuvad kui pidulik luuletus. Hea meel on selle üle, et ka meie väärtuslik ladinakeelne kultuuripärand on viimastel aastakümnetel tänu klassikaliste filoloogide tublile tööle nähtavamaks saanud. Gösekeni köitest võime muu hulgas lugeda nelja ladinakeelse pühendusluuletuse esmatõlget Tafenault (Kingisepp jt 2010: 104-109). Hea on ka see, et tõlkimisega kaasnevad uued tõlgendused. Vana kirjakeele töörühma ja Lepajõe novaatoriosast oli juba veidi juttu; lisagem sellesse ritta veel nt Habichti Stahli-uurimused, Pille Penjami tööd vana kirjakeele verbisüntaksi kohta ja Tafenau hiljutine tore leid, Gösekeni sõnaraamatu seni märkamata eeskuju (Tafenau 2011a). Esileküündivad on aga ka Rossi ja tema kolleegide uurimused seoses meie piiblitõlkelooga. Käesoleva kirjutise kontekstis tõstan esile Rossi saateartiklit, milles võrreldakse Thor Helle grammatika ja eesti piiblitõlke morfosüntaktilisi ja leksikaalseid suundumusi (Ross 2006), ja Tafenau doktoriväitekirja (2011b).

Meie kultuuriruumis on juubelid sageli sündmused, mis meid tulemuslikule tööle kannustavad. Kiirustada siiski ei maksa. Tekstikriitiliste teadusväljaannete ettevalmistamisel - ja sellised on kõik meie vanade grammatikate tõlked - tasub meeles pidada, et sajandite palge ees pole sellel mingit tähtsust, kas meie uusüllitis ilmub aastal x või x +2 , tähtis on, et ta ilmuks parimal kujul, milleks me parajasti võimelised oleme.

\section{Kirjandus}

Gutslaff, Johannes 1998. Observationes grammaticae circa linguam Esthonicam. Grammatilisi vaatlusi eesti keelest. Tõlk. ja väljaande koost. Marju Lepajõe. Toim. Jaak Peebo. (= Tartu Ülikooli eesti keele õppetooli toimetised 10.) Tartu. 
Habicht, Külli 2010. Saateks. - Valve-Liivi Kingisepp, Kristel Ress, Kai Tafenau. Heinrich Gösekeni grammatika ja sõnastik 350. Toim. Külli Habicht, Külli Prillop. Tartu Ülikooli eesti ja üldkeeleteaduse instituut. Tartu: Tartu Ülikool, 7-10.

Habicht jt 2006 = Külli Habicht, Valve-Liivi Kingisepp, Külli Prillop. Uudne sõnaraamat vanadest tekstidest. - Keel ja Kirjandus 5, 365-375.

Kikas, Kristel 2002. Mida sisaldab Heinrich Stahli „Vocabula”? Toim. ValveLiivi Kingisepp. (= Tartu Ülikooli eesti keele õppetooli toimetised 21.) Tartu: Tartu Ülikooli kirjastus.

Kilgi, Ross 2006 = Lühike sissejuhatus eesti keelde 1732. [Anton Thor Helle] Saksa keelest tõlk. ja järelsõnad kirj. Annika Kilgi, Kristiina Ross. Eesti Keele Instituut. Tallinn: Eesti Keele Sihtasutus.

Kingisepp, Valve-Liivi 2002. Saateks. - Kristel Kikas. Mida sisaldab Heinrich Stahli „Vocabula”? Toim. Valve-Liivi Kingisepp. (= Tartu Ülikooli eesti keele õppetooli toimetised 21.) Tartu: Tartu Ülikooli kirjastus, 7-8.

Kingisepp jt 2010 = Valve-Liivi Kingisepp, Kristel Ress, Kai Tafenau. Heinrich Gösekeni grammatika ja sõnastik 350. Toim. Külli Habicht, Külli Prillop. Tartu Ülikooli eesti ja üldkeeleteaduse instituut. Tartu: Tartu Ülikool.

Lepajõe, Marju 1985. Johannes Gutslaffi „Observationes grammaticae circa linguam Esthonicam" tõlge. Käsikirjaline diplomitöö. Tartu Ülikool. Eesti keele osakond.

Lepajõe, Marju 1998a. Grammatikas esinevate eesti sõnade indeks. - Johannes Gutslaff. Observationes grammaticae circa linguam Esthonicam. Grammatilisi vaatlusi eesti keelest. Tõlk. ja väljaande koost. Marju Lepajõe. Toim. Jaak Peebo. (= Tartu Ülikooli eesti keele õppetooli toimetised 10.) Tartu: Tartu Ülikool, 247-279.

Lepajõe, Marju 1998b. Johannes Gutslaffi „Grammatilised vaatlused”. Johannes Gutslaff. Observationes grammaticae circa linguam Esthonicam. Grammatilisi vaatlusi eesti keelest. Tõlk. ja väljaande koost. Marju Lepajõe. Toim. Jaak Peebo. (= Tartu Ülikooli eesti keele õppetooli toimetised 10.) Tartu: Tartu Ülikool, 285-316.

Lepajõe, Marju 1998c. Märkused. - Johannes Gutslaff. Observationes grammaticae circa linguam Esthonicam. Grammatilisi vaatlusi eesti keelest. Tõlk. ja väljaande koost. Marju Lepajõe. Toim. Jaak Peebo. (= Tartu Ülikooli eesti keele õppetooli toimetised 10.) Tartu: Tartu Ülikool, 280-284.

Prillop, Külli 2004. Kuidas märksõnastada vanu eestikeelseid tekste? - Keel ja Kirjandus 2, 90-99.

Ress, Kristel 2009. XVII sajandi saksa-eesti sõnastike töötlemise probleemidest. - Keel ja Kirjandus 8-9, 631-641.

Ress, Kristel 2010. Sõnaraamatu kasutajale. - Valve-Liivi Kingisepp, Kristel Ress, Kai Tafenau. Heinrich Gösekeni grammatika ja sõnastik 350. 
Toim. Külli Habicht, Külli Prillop. Tartu Ülikooli eesti ja üldkeeleteaduse instituut. Tartu: Tartu Ülikool, 27-35.

Ross 2003 = Uue ajastu misjonilingvist. Eduard Ahrens 200. Koost. ja toim. Kristiina Ross. Eesti Keele Instituut. Tallinn: Eesti Keele Sihtasutus.

Ross, Kristiina 2006. „Lühike sissejuhatus” ja eesti piiblitõlge. - Annika Kilgi, Kristiina Ross. Lühike sissejuhatus eesti keelde 1732. [Anton Thor Helle] Saksa keelest tõlk. ja järelsõna kirj. Annika Kilgi, Kristiina Ross. Eesti Keele Instituut. Tallinn: Eesti Keele Sihtasutus, C26-C53.

Rätsep, Huno 1987. Heinrich Stahli keeleõpetus oma aja peeglis. - Keel ja Kirjandus 12, 709-715.

Tafenau, Kai 2011a. Heinrich Gösekeni sõnaraamatu seni märkamata eeskuju. - Keel ja Kirjandus 6, 425-439.

Tafenau, Kai 2011b. Uue Testamendi tõlkimisest Rootsi ajal: käsikirjad, tõlkijad ja eesti kirjakeel. (= Dissertationes philologiae estonicae Universitatis Tartuensis 27.) Tartu: Tartu Ülikooli kirjastus.

Viitkar, Urve 2005. Johannes Gutslaffi „Observationes grammaticae circa linguam Esthonicam” (1648). Bakalaureusetöö Tartu Ülikooli eesti ja üldkeeleteaduse instituudi eesti keele osakonnas.

Värri Haarmann 1977 = Die estnischen Grammatiken des 17. Jahrhunderts. II. Heinrich Göseken. Manuductio ad Linguam Oesthonicam. Anführung zur Öhstnischen Sprache. Reval 1660. Hrsg. Anna-Lisa Värri Haarmann. (= Fenno-Ugrica 3.) Hamburg: Helmut Buske Verlag.

Wiedemann, Ferdinand Johann 2002. Uurimus Võru murdest. Versuch ueber den Werroehstnischen Dialekt. Tõlk. Inge Annom. Toim. Külli Habicht, Karl Pajusalu. (= Tartu Ülikooli eesti keele õppetooli toimetised 20.) Tartu.

Wiedemann, Ferdinand Johann 2005. Grammatik der estnischen Sprache. Durchgesehenes Faksimile der Ausgabe von 1875. Hrsg. Karl Pajusalu, Urmas Sutrop. Estnische Gesellschaft für Muttersprache. Tallinn: Stiftung für Estnische Sprache.

Wiedemann, Ferdinand Johann 2011. Eesti keele grammatika. Tõlk. Heli Laanekask. Toim. Ellen Niit. Eesti Teaduste Akadeemia Emakeele Selts. Tallinn. 


\title{
Centuries within one's reach: Translations of old Estonian grammars
}

\author{
Heli Laanekask
}

The article analyses the Estonian translations of 17th-19th-century grammars of the Estonian language written in foreign languages and the new editions of multilingual glossaries included in those grammars. The article mainly concentrates on Heinrich Gösekeni grammatika ja sõnastik 350 [Heinrich Göseken’s Grammar and Glossary 350] by V.-L. Kingisepp, K. Ress, and K.Tafenau (Tartu, 2010), but it also deals with M. Lepajõe's translation of Gutslaff's grammar (J. Gutslaff, Observationis grammaticae circa linguam Esthonicam. Grammatilisi vaatlusi eesti keelest [Grammatical Observations of the Estonian Language], Tartu, 1998); I. Annom's translation of F. J. Wiedemann's Uurimus Võru murdest [A Study of the Võru Dialect] (Tartu, 2002); K. Kikas' study Mida sisaldab Heinrich Stahli Vocabula? [What Does H. Stahl's Vocabula Include?] (Tartu, 2002); E. Ahrens' grammar translated by $\mathrm{K}$. Ross et al. in the book Uue ajastu misjonilingvist. Eduard Ahrens 200 [A Missionary Linguist of the New Era. Eduard Ahrens 200] (Tallinn, 2003); and the translation of Thor Helle's grammar by A. Kilk and K. Ross in their book Lühike sissejuhatus eesti keelde 1732 [A Short Introduction to the Estonian Language 1732] (Tallinn, 2006). The article gives a critical observation of the structure and comments to the translated works and discusses different solutions for translating old terminology, explaining archaic Estonian, and disclosing the linguistic riches of the glossaries.

Key words: descriptions of Estonian grammar, Estonian lexicography, multilingual glossaries, history of written Estonian, translation, text-critical editions

Heli Laanekask

eesti ja üldkeeleteaduse instituut

Tartu Ülikool

Jakobi 2

51014 Tartu

heli.laanekask@ut.ee 